\title{
Association Between ALT Level and the Rate of Cardio/Cerebrovascular Events in HIV-Positive Individuals: The D:A:D Study
}

\author{
Caroline A. Sabin, PhD, * Lene Ryom, MD, $+\neq$ Helen Kovari, MD, $\S$ Ole Kirk, MD, DMSci, $\dagger \neq$ \\ Stephane de Wit, MD, \| Matthew Law, PhD, $\mid$ Peter Reiss, MD, \# Francois Dabis, MD, ** \\ Christian Pradier, MD, $\dagger$ Wafaa El-Sadr, MD, $\neq$ Antonella d'Arminio Monforte, MD, $\S \S$ \\ David Kamara, MSc,* Andrew N. Phillips, PhD,* and Jens D. Lundgren, MD $\$$ t
}

Background: An inverse association between serum alanine
aminotransferase (ALT) levels and the risk of myocardial
infarction (MI) has been reported in the general population. We
investigated associations between ALT levels and the risk of

various cardiovascular and cerebrovascular outcomes in a large cohort study of HIV-positive individuals.

Methods: Using Poisson regression, we investigated associations between the latest ALT level and MI, coronary heart disease (CHD),

Received for publication December 19, 2012; accepted February 26, 2013.

From the *Research Department of Infection and Population Health, UCL, London, United Kingdom; †Copenhagen HIV Programme, University of Copenhagen, Copenhagen, Denmark; †Division of Infectious Diseases and Hospital Epidemiology, University Hospital Zurich, University of Zurich, Zurich, Switzerland; §Epidemiklinikken M5132, Copenhagen Univ Hosp/Rigshospitalet, Copenhagen, Denmark; |Department of Infectious Diseases, CHU Saint-Pierre Hospital, Brussels, Belgium; $₫$ Kirby Institute, University of New South Wales, Sydney, Australia; \#Academic Medical Center, Amsterdam, the Netherlands; **Université Bordeaux, ISPED, Centre INSERM U897- Epidémiologie-Biostatistique and INSERM, ISPED, Centre INSERM U897-Epidémiologie-Biostatistique, Bordeaux, France ††Département de santé publique, Centre Hospitalier Universitaire, Nice-Sophia-Antipolis University, Nice, France; ††ICAP, Columbia University/Harlem Hospital, New York, NY; and §§Infectious Diseases Unit, Department of Health Sciences, University of Milan, San Paolo University Hospital, Milan, Italy.

Supported by the Highly Active Antiretroviral Therapy Oversight Committee (HAART-OC), a collaborative committee with representation from academic institutions; the European Agency for the Evaluation of Medicinal Products; the United States Food and Drug Administration; the patient community; and all pharmaceutical companies with licensed anti-HIV drugs in the European Union: Abbott Laboratories, Boehringer Ingelheim Pharmaceuticals, Inc., Bristol-Myers Squibb, Gilead Sciences, Inc., Viiv Healthcare, Merck \& Co, Inc., Pfizer, Inc, F. Hoffman-LaRoche, Ltd., and Janssen Pharmaceuticals. Supported by a grant [grant number CURE/97-46486] from the Health Insurance Fund Council, Amstelveen, the Netherlands, to the AIDS Therapy Evaluation Project Netherlands (ATHENA); by a grant from the Agence Nationale de Recherches sur le SIDA [grant number Action Coordonnée no.7, Cohortes], to the Aquitaine Cohort; The Australian HIV Observational Database (AHOD) is funded as part of the Asia Pacific HIV Observational Database, a program of The Foundation for AIDS Research, amfAR, and is supported in part by a grant from the U.S. National Institutes of Health's National Institute of Allergy and Infectious Diseases (NIAID) [grant number U01AI069907] and by unconditional grants from Merck Sharp \& Dohme, Gilead Sciences, Bristol-Myers Squibb, Boehringer Ingelheim Pharmaceuticals, Inc., Roche, Pfizer, GlaxoSmithKline, and Janssen Pharmaceuticals. The Kirby Institute is funded by The Australian Government Department of Health and Ageing, and is affiliated with the Faculty of Medicine, The University of New South Wales. By grants from the Fondo de Investigación Sanitaria [grant number FIS 99/0887] and Fundación para la Investigación y la Prevención del SIDA en Espanã [grant number FIPSE 3171/00], to the Barcelona Antiretroviral Surveillance Study (BASS); by the National Institute of Allergy and Infectious Diseases, National Institutes of Health [grants number 5U01AI042170-10, 5U01AI046362-03], to the Terry Beirn Community Programs for Clinical Research on AIDS (CPCRA); by grants from the BIOMED 1 [grant number CT94-1637] and BIOMED 2 [grant number CT97-2713] programs and the fifth framework program [grant number QLK2-2000-00773] of the European Commission and grants from Bristol-Myers Squibb, GlaxoSmithKline, Boehringer Ingelheim Pharmaceuticals, Inc., and Roche, to the EuroSIDA study; by unrestricted educational grants of Abbott Laboratories, Bristol-Myers Squibb, Gilead Sciences, Inc., GlaxoSmithKline, Pfizer, Inc., Janssen Pharmaceuticals to the Italian Cohort Naive to Antiretrovirals (The ICONA Foundation); and by a grant from the Swiss National Science Foundation, to the Swiss HIV Cohort Study (SHCS).

M. L. has received unconditional grants from Merck Sharp \& Dohme, Gilead; Bristol-Myers Squibb, Boehringer Ingelheim, Roche, Pfizer, GlaxoSmithKline, and Janssen-Cilag. S. d. has received honoraria from Bristol-Myers Squibb and Viiv Healthcare. A. N. P. has received funding for consultancy from Gilead Sciences, Bristol-Myers Squibb, Johnson \& Johnson, Viiv Healthcare, and GSK Bio. A. d'A. M. has received funding for Advisory Board membership for Bristol-Myer Squibb, Abbott, Janssen, Gilead Sciences, and Viiv Healthcare. P. R. has served as a scientific advisor to Bristol-Myers Squibb, Gilead Sciences, Grupo Ferrer, GlaxoSmithKline, Janssen, Merck Sharp \& Dohme, and ViiV Healthcare. He has served on data safety monitoring boards and endpoint adjudication committees for Janssen and his institution has received honoraria for speaking engagements at scientific conferences from Bristol-Myers Squibb, Gilead Sciences, and GSK. He has received research support from Gilead Sciences, Viiv Healthcare, Merck Sharp \& Dohme, Janssen, Bristol-Myers Squibb, Abbott Laboratories, and Boehringer Ingelheim. O. K. has received honoraria, consultancy, lecture fees, and travel grants from Abbott Laboratories, Bristol-Myers Squibb, Gilead Sciences, Janssen, Merck Sharp \& Dohme, Roche, and Viiv Healthcare. C. P. has received honoraria from Viiv Healthcare, Abbott Pharmaceuticals, and Merck Sharp \& Dohme. C. A. S. has received funding for Advisory Board membership, speaker panels, and provision of educational materials for Gilead Sciences, Abbott Pharmaceuticals, Viiv Healthcare, Merck Sharp \& Dohme, Janssen-Cilag, and Bristol-Myers Squibb. H. K., F. D., W. E., D. K., L. R., J. D. L. have no conflicts of interest to disclose.

C. A. S. developed the initial study protocol. L. R. prepared study co-ordination, prepared the datasets for analysis and assisted with endpoint review. C. A. S. performed all statistical analysis and prepared the initial draft of the manuscript. All authors have provided management input to the D:A:D Study, contributed datasets, provided input to the development of the manuscript and have seen and approved the final version.

The content of this publication is solely the responsibility of the authors and does not necessarily represent the official views of any of the institutions mentioned above. The D:A:D participating cohorts and Steering Committee are listed in Appendix 1.

Correspondence to: Caroline A. Sabin, Research Department of Infection and Population Health, UCL, Royal Free Campus, Rowland Hill Street, London NW3 2PF, United Kingdom (e-mail: c.sabin@ucl.ac.uk).

Copyright $(\subseteq 2013$ by Lippincott Williams \& Wilkins 
and stroke, after adjusting for known confounders and cumulative/ recent exposure to antiretroviral drugs. Analyses were also performed for the end points of all-cause/liver-related mortality and new-onset diabetes mellitus.

Results: By February 2011, participants had experienced 541 MIs, $804 \mathrm{CHD}$, and 258 stroke events. The MI rate decreased from $3.1 / 1000$ person-years among those with ALT $\leq 18 \mathrm{U} / \mathrm{L}$ to $2.1 / 1000$ person-years among those with ALT $>60 \mathrm{U} / \mathrm{L}$. After adjustment for confounders, each 2-fold increment in ALT was associated with a $19 \%$ drop in the MI rate relative rate, 0.81 [95\% confidence interval (CI): 0.74 to 0.89 ], $P=0.0001\}$. A weaker inverse association was seen for CHD with no indication of a linear association between ALT levels and stroke $(P=0.72)$. Adjusted relative rates were 0.88 (95\% CI: 0.81 to 0.97$)$ and 0.70 (95\% CI: 0.54 to 0.92$)$ in those who were hepatitis $\mathrm{C}$ virus negative and hepatitis $\mathrm{C}$ virus positive, respectively, and 0.72 (95\% CI: 0.58 to 0.89$)$ and 0.84 ( 0.77 to 0.93$)$ in injection drug users and non-injection drug users, respectively. Liver-related mortality and diabetes both demonstrated a positive association with ALT levels, whereas all-cause mortality showed a U-shaped relationship.

Conclusions: Higher ALT levels are associated with lower MI risk in HIV-positive individuals, but with higher risks of liver-related mortality and diabetes mellitus.

Key Words: myocardial infarction, alanine aminotransferase, cardiovascular disease, coronary heart disease, stroke

(J Acquir Immune Defic Syndr 2013;63:456-463)

\section{INTRODUCTION}

High serum alanine aminotransferase (ALT) levels have been reported to be associated with an increased risk of several outcomes in both the general and HIV-positive populations, including diabetes, nonalcoholic fatty liver disease, and both liver-related and all-cause mortality. ${ }^{1-5}$ In contrast, Ford et $\mathrm{al}^{6}$ recently reported the unexpected finding that among individuals recruited to 3 general population cohorts [the West of Scotland Coronary Prevention Study (WOSCOPS), the Prospective Study of Pravastatin in the Elderly at Risk (PROSPER), and the Leiden 85-plus Study], there were inverse associations between baseline ALT levels within the normal range and all-cause mortality (over a period of follow-up that ranged from around 4 to 16 years in the 3 cohorts) and mortality from coronary heart disease (CHD), cancer, and other non-cardiovascular causes. These associations remained after adjustment for measured confounders. Individuals included in the studies were aged from 45 to 85 years, and the predictive ability of ALT levels was found across the normal range of values. The authors could not demonstrate a mechanism for their findings, but speculated that the inverse associations might reflect impaired synthetic capacity in the liver, reduced liver cell turnover, or low skeletal muscle mass, all of which might, themselves, be associated with increased mortality.

HIV-positive individuals are at a high risk of elevated transaminase levels as a result of coinfection with hepatitis B or $\mathrm{C}$, lifestyle factors (alcohol and drug use), and treatment with some antiretroviral drugs. ${ }^{7-10}$ Furthermore, there is increasing evidence that HIV also plays a role in the development of cardiovascular disease (CVD), possibly through inflammatory processes, and some antiretroviral drugs also raise CVD risk. $^{11-13}$ We investigated associations between ALT levels and the risk of various cardiovascular and cerebrovascular outcomes, primarily focusing on myocardial infarction (MI), in the Data Collection on Adverse Events of Anti-HIV Drugs (D:A:D) Study.

\section{METHODS}

The design of the D:A:D Study has been described in detail elsewhere. ${ }^{13,14}$ In brief, it is an observational study of $>49,000 \mathrm{HIV}$-positive people under care for HIV from 11 cohorts from Europe, Australia, and the United States. All participants were under active follow-up in their cohorts at the time of enrollment in the study. The primary study aim was to investigate the associations between use of antiretroviral drugs and risk of CVD and other major clinical events. Data are collected prospectively during routine clinic visits; the standardized dataset includes information on sociodemographic factors, AIDS events and deaths, known risk factors for CVD, laboratory markers for monitoring HIV (including CD4 count and HIV RNA) and CVD, antiretroviral treatment, and treatments that influence CVD risk. Information on all incident cases of CVD is reported to the study coordinating center for validation and coding that is performed blind to the patient's antiretroviral treatment status. Information on cause of death was captured using the Coding of Causes of Death in HIV (CoDe) form. ${ }^{15,16}$ The present analyses were limited to the participating cohorts that provided data on ALT levels.

\section{Statistical Methods}

Follow-up time for the analysis was considered from the date of recruitment to the D:A:D Study until the earliest of a new event, death, February 1, 2011, or 6 months after the individual's last clinic visit. For our primary analyses, we considered the following events: (1) MI; (2) CHD: MI, sudden cardiac death, or invasive procedure (coronary artery bypass graft, carotid endarterectomy, or angioplasty); or (3) Confirmed stroke. Each individual's follow-up was split into a series of consecutive 1-month periods and his/her clinical, immunologic, and virological status at the start of each period was established (using the most recently available information before the start of each period). Each individual's latest ALT level was categorized (Table 1), and event rates were calculated for each stratum. Analyses were performed using Poisson regression with adjustment for potential confounders (for nonstroke end points: gender, age, race, mode of HIV acquisition, previous and family history of CVD, body mass index, smoking status, clinical cohort, calendar year, cumulative exposure to each specific antiretroviral drug, and recent exposure to drugs in the nucleoside reverse transcriptase inhibitor class; for the stroke end point: gender, age, previous history of CVD, body mass index, smoking status, hypertension, and calendar year). Analyses were also performed with the latest ALT level included as a continuous covariate (after $\log _{2}$ transformation). To further assess whether our results were driven by individuals 
TABLE 1. Characteristics of 31,235 Individuals at Entry to the Study

\begin{tabular}{lc}
\hline & $\mathbf{n ~ ( \% )}$ \\
\hline Gender, n (\%) & \\
Male & $22,788(73.0)$ \\
Female & $8447(27.0)$ \\
Mode of HIV acquisition, n (\%) & \\
Sex between men & $12,950(41.5)$ \\
Injection drug use & $5307(17.0)$ \\
Sex between men and women & $10,763(34.5)$ \\
Other/unknown & $2215(7.1)$ \\
Ethnicity, n (\%) & \\
White & $16,630(53.2)$ \\
Black African & $2188(7.0)$ \\
Other & $436(1.4)$ \\
Unknown & $11,981(38.4)$ \\
Age (yrs), median (IQR) & $37(32-44)$ \\
Prior antiretroviral therapy, $\mathrm{n}(\%)$ & $20,816(66.6)$ \\
HIV RNA $\leq 50$ copies per mL, $\mathrm{n}(\%)$ & $8502(29.0)$ \\
CD4 count (cells/mm $\left.{ }^{3}\right)$, median (IQR) & $405(249-591)$ \\
\hline
\end{tabular}

who were coinfected with hepatitis C virus (HCV) or who had a reported history of injection drug use, our analyses were repeated after stratifying by these factors.

Several sensitivity analyses were also performed for the MI end point. (1) To investigate possible mechanisms for any associations seen, we performed analyses that additionally adjusted for the latest levels of total cholesterol and triglyceride. (2) As statin use has been reported to lead to an increased risk of diabetes and elevated ALT levels, ${ }^{17}$ analyses also included adjustment for exposure to lipid-lowering drugs. (3) As patients with elevated ALT may die from competing causes (eg, liver failure), we performed an analysis after excluding all patients from the dataset who died of non-CVD causes without having an MI. (4) As ALT levels are highly variable measurements, ${ }^{7}$ analyses were repeated after smoothing the longitudinal ALT levels using a running median of the 3 preceding values. (5) Analyses were repeated after excluding periods of follow-up when an individual's ALT level had not been measured within the past 6 months. Results of all sensitivity analyses were consistent with our main analyses and are described only in brief.

Although the cardiovascular and cerebrovascular events were of primary interest, analyses were also performed considering all-cause mortality, liver-related mortality, and new-onset diabetes mellitus as secondary end points. These secondary end points were chosen as positive controls as the published literature would suggest that higher ALT levels should be associated with higher risk of liver-related mortality and diabetes mellitus; predicted associations with all-cause mortality are unclear given the many different causes of death in the cohort.

\section{RESULTS}

The study population (from 8 of the 11 participating cohorts) included 31,235 participants. Three-quarters (73.0\%) of participants were male; ethnic group was white in $53.2 \%$, black in $7.0 \%$, other in $1.4 \%$, and unknown/not recorded in $38.4 \%$ (Table 1). At entry to the study, the median [interquartile range (IQR)] age of patients was $37(32-44)$ years and $66.6 \%$ had been exposed to antiretroviral therapy. The median (IQR) CD4 count of participants was 405 (249-591) cells $/ \mathrm{mm}^{3}$, and HIV RNA was $3.0(1.7-4.5) \log _{10}$ copies per milliliter.

By February 1, 2011, the participants had experienced 541 MIs over 200,815 person-years follow-up \{PYFU; 2.7/1000 PYFU [95\% confidence interval (CI): 2.5 to 2.9]\}, 804 CHD events over 199,972 PYFU [4.0/1000 (95\% CI: 3.7 to 4.3) PYFU] and 258 stroke events over 201,925 PYFU [1.3/1000 (95\% CI: 1.1 to 1.4) PYFU]. Patients contributed a median (IQR) of 10 (4-18) ALT measurements to the analysis; ALT levels were measured a median (IQR) of 144 (94-186) days apart. Overall, the median ALT level was 28 (IQR: 19-46) U/L with no evidence of a change in level over time [median (IQR): 28 (18-52) U/L for measurements taken in 2000, 28 (20-43) U/L for measurements taken in 2010/2011]. As expected, ALT values were higher in men, those who were older, injection drug users, those of white or unknown race, those with an existing diagnosis of diabetes, and those coinfected with hepatitis B virus or HCV, whereas levels were lower in those of black African race and in those with a BMI $<18 \mathrm{~kg} / \mathrm{m}^{2}$ (data not shown).

The MI event rate decreased from 3.1/1000 PYFU among those with a latest ALT level $\leq 18 \mathrm{U} / \mathrm{L}$ to $2.1 / 1000$ PYFU among those with a latest ALT level $>60 \mathrm{U} / \mathrm{L}$ (Table 2). After adjustment for known CVD risk factors, calendar year, and cumulative/recent exposure to each antiretroviral drug, there was a clear reduction in MI risk as the ALT level increased, each 2-fold $\left(\log _{2}\right)$ increment in ALT being associated with a $19 \%$ drop in the MI rate [0.81 (95\% CI: 0.74 to 0.89 ), $P=0.0001]$. Exclusion of individuals with an ALT level above the upper limit of normal (taken to be $40 \mathrm{IU}$ for the purposes of this analysis) resulted in a similar estimate [0.80 (95\% CI: 0.68 to 0.95$)$ ]. In contrast, although an inverse association was seen with the CHD end point $[0.92$ (95\% CI: 0.86 to 0.99 ), $P=0.02$ ], this appeared to be much weaker than that for MI (an 8\% reduction in the risk of CHD for each 2-fold increment in ALT level), and there was no clear indication of a linear association between ALT levels and the risk of stroke $(P=0.72)$. Thus, the negative association appeared to be specific to MI and did not extend to other cardio/cerebrovascular end points evaluated.

The estimated adjusted association between MI and the latest ALT level did not change after further adjustment for the latest triglyceride/total cholesterol levels [0.81 (95\% CI: 0.74 to 0.88$), P=0.0001]$, or for the use of lipid-lowering drugs [0.81 (95\% CI: 0.74 to 0.88$), P=0.0001]$. After excluding from analysis those patients who died from nonCVD-related causes, the association between the latest ALT level and MI risk was again unchanged [0.82 (95\% CI: 0.75 to 0.89$), P=0.0001]$. Analyses were repeated after smoothing the longitudinal ALT levels before $\log _{2}$ transformation using a running median, again with consistent results $[0.79(95 \%$ CI: 0.72 to 0.87$), P=0.0001$ ]. The adjusted relative rate was 0.88 ( 0.81 to 0.97$)$ in those who were HCV negative and 0.70 ( $95 \%$ CI: 0.54 to 0.92 ) in those who were $\mathrm{HCV}$ positive 
TABLE 2. MI, CHD, and Stroke Event Rates Stratified by Latest (Time-Updated) ALT Level, Unadjusted, and Adjusted* Associations Between the Latest ALT Level and Each Outcome

\begin{tabular}{|c|c|c|c|c|c|c|c|}
\hline \multirow{2}{*}{$\begin{array}{l}\text { Latest ALT } \\
\text { Level (U/L) }\end{array}$} & \multirow[b]{2}{*}{ Events } & \multirow[b]{2}{*}{ PYFU } & \multirow{2}{*}{$\begin{array}{c}\text { Rate (per } 1000 \text { PYFU) } \\
(95 \% \text { CI })\end{array}$} & \multicolumn{4}{|c|}{ Relative Rate (95\% CI) } \\
\hline & & & & Unadjusted & $P$ & Adjusted* & $P$ \\
\hline \multicolumn{8}{|l|}{ MI } \\
\hline$\leq 18$ & 119 & 38,354 & $3.1(2.6$ to 3.7$)$ & 1 & - & 1 & - \\
\hline$>18$ to $\leq 25$ & 98 & 34,584 & $2.8(2.3$ to 3.4$)$ & $0.91(0.70$ to 1.19$)$ & 0.51 & $0.80(0.61$ to 1.05$)$ & 0.10 \\
\hline$>25$ to $\leq 35$ & 99 & 34,436 & $2.9(2.3$ to 3.4$)$ & $0.93(0.71$ to 1.21$)$ & 0.58 & $0.78(0.60$ to 1.03$)$ & 0.08 \\
\hline$>35$ to $\leq 60$ & 83 & 35,502 & $2.3(1.8$ to 2.8$)$ & $0.75(0.57$ to 1.00$)$ & 0.05 & $0.60(0.45$ to 0.80$)$ & 0.0005 \\
\hline$>60$ & 72 & 34,050 & 2.1 (1.6 to 2.6$)$ & $0.68(0.51$ to 0.91$)$ & 0.01 & $0.50(0.37$ to 0.68$)$ & 0.0001 \\
\hline Not known & 70 & 23,889 & $2.9(2.2$ to 3.6$)$ & $0.94(0.70$ to 1.27$)$ & 0.70 & $0.65(0.45$ to 0.93$)$ & 0.02 \\
\hline$/ \log _{2}$ increment & & & & $0.89(0.82$ to 0.96$)$ & 0.004 & $0.81(0.74$ to 0.89$)$ & 0.0001 \\
\hline \multicolumn{8}{|l|}{ CHD } \\
\hline$\leq 18$ & 166 & 38,230 & $4.3(3.7$ to 5.0$)$ & 1 & - & 1 & - \\
\hline$>18$ to $\leq 25$ & 144 & 34,445 & $4.2(3.5$ to 4.9$)$ & $0.96(0.77$ to 1.20$)$ & 0.74 & $0.87(0.70$ to 1.09$)$ & 0.24 \\
\hline$>25$ to $\leq 35$ & 153 & 34,246 & $4.5(3.8$ to 5.2$)$ & $1.03(0.83$ to 1.28$)$ & 0.80 & $0.92(0.73$ to 1.15$)$ & 0.45 \\
\hline$>35$ to $\leq 60$ & 124 & 35,313 & $3.5(2.9$ to 4.1$)$ & $0.81(0.64$ to 1.02$)$ & 0.07 & $0.72(0.57$ to 0.91$)$ & 0.005 \\
\hline$>60$ & 122 & 33,918 & $3.6(3.0$ to 4.2$)$ & $0.83(0.66$ to 1.05$)$ & 0.11 & $0.76(0.60$ to 0.97$)$ & 0.03 \\
\hline Not known & 95 & 23,820 & $4.0(3.2$ to 4.8$)$ & $0.92(0.71$ to 1.18$)$ & 0.51 & $0.73(0.57$ to 0.94$)$ & 0.02 \\
\hline$/ \log _{2}$ increment & & & & $0.94(0.88$ to 1.00$)$ & 0.07 & $0.92(0.86$ to 0.99$)$ & 0.02 \\
\hline \multicolumn{8}{|l|}{ Confirmed stroke } \\
\hline$\leq 18$ & 65 & 38,484 & $1.7(1.3$ to 2.1$)$ & 1 & - & 1 & - \\
\hline$>18$ to $\leq 25$ & 42 & 34,770 & $1.2(0.8$ to 1.6$)$ & $0.72(0.49$ to 1.05$)$ & 0.09 & $0.67(0.45$ to 0.99$)$ & 0.05 \\
\hline$>25$ to $\leq 35$ & 37 & 34,697 & $1.1(0.7$ to 1.4$)$ & $0.63(0.42$ to 0.95$)$ & 0.03 & $0.58(0.39$ to 0.88$)$ & 0.01 \\
\hline$>35$ to $\leq 60$ & 31 & 35,749 & $0.9(0.6$ to 1.2$)$ & $0.51(0.33$ to 0.79$)$ & 0.002 & $0.48(0.31$ to 0.74$)$ & 0.001 \\
\hline$>60$ & 56 & 34,222 & $1.6(1.2$ to 2.1$)$ & $0.97(0.68$ to 1.38$)$ & 0.86 & $0.97(0.67$ to 1.40$)$ & 0.88 \\
\hline Not known & 27 & 24,003 & $1.1(0.7$ to 1.6$)$ & $0.67(0.43$ to 1.04$)$ & 0.08 & $0.64(0.41$ to 1.01$)$ & 0.06 \\
\hline$/ \log _{2}$ increment & & & & $0.98(0.87$ to 1.09$)$ & 0.004 & $0.98(0.87$ to 1.10$)$ & 0.72 \\
\hline
\end{tabular}

*Analyses of MI adjusted for demographic and CVD risk factors and cumulative exposure to specific antiretroviral drugs, and recent exposure to drugs from the nucleoside reverse transcriptase inhibitor class; analyses of stroke adjusted for gender, age, previous history of CVD, body mass index, smoking status, hypertension, and calendar year.

$(P$ value for interaction $=0.15)$; the adjusted relative rates were $0.72(95 \% \mathrm{CI}$ : 0.58 to 0.89$)$ in injection drug users and 0.84 (95\% CI: 0.77 to 0.93$)$ in non-injection drug users $(P$ value for interaction $=0.14)$. Finally, after excluding periods of follow-up when an individual's ALT level had not been measured in the past 6 months, the results were similar [95\% CI: 0.77 (0.69 to 0.87$), P=0.0001]$.

Analyses of non-cardio/cerebrovascular end points (Table 3) supported our predefined hypothesized associations. Both liver-related mortality and diabetes demonstrated a positive association with ALT levels (ie, higher levels were associated with increased risk of each event), whereas allcause mortality showed a U-shaped relationship with higher mortality levels in those with either very low $(<18 \mathrm{U} / \mathrm{L})$ or very high $(>60 \mathrm{U} / \mathrm{L})$ ALT levels, presumably reflecting different associations with ALT and specific causes of mortality in the cohort.

\section{DISCUSSION}

Using the data from a large prospective study of HIVpositive individuals, we have confirmed the unexpected findings from Ford et $\mathrm{al}^{6}$ of an inverse association between an individual's ALT level and his/her risk of MI. In particular, we found that there was a linear relationship with the latest ALT level, with the risk of MI progressively decreasing as the
ALT level increased. Our findings were robust to variations in the measurement of ALT and could not be explained by a higher rate of mortality from competing causes in those with higher ALT levels.

In contrast to Ford's analysis, where inverse associations were also seen with all-cause mortality, cancer deaths (not evaluated as part of the present analysis), and other cardio/cerebrovascular end points, our association with ALT did appear to be specific to the MI end point. However, it should be noted that whereas the cohorts included in Ford's study included individuals whose ALT levels were largely in the normal range, HIV-positive individuals in the D:A:D Study generally have higher ALT levels (eg, around $20 \%$ of followup time was spent with an ALT level of $>60 \mathrm{U} / \mathrm{L}$ ); thus, it is likely that the strong positive associations between ALT and liver-related mortality and diabetes are driven by individuals with ALT levels at the higher end of the normal range or above. Of note, our findings relating to MI risk, and those of Ford, are inconsistent with those of Schindhelm et $\mathrm{al}^{18}$ who noted a higher rate of fatal and nonfatal CHD events in those with higher ALT levels.

Consistent with other published data, a higher ALT level was associated with an increased risk of diabetes mellitus. ${ }^{4}$ Not surprisingly, we found an increased risk of liver-related mortality in those with very high ALT levels in 
TABLE 3. Adjusted* Associations Between Latest ALT Level and Event Rates for (1) All-Cause Mortality, (2) Liver-Related Mortality, and (3) Diabetes

\begin{tabular}{|c|c|c|}
\hline Latest ALT Level (U/L) & Relative Rate $(95 \%$ CI) & $\boldsymbol{P}$ \\
\hline \multicolumn{3}{|c|}{$\begin{array}{l}\text { All-cause mortality [2230 events, } 202,727 \text { PYFU, rate }(95 \% \text { CI }) / 1000 \text { PYFU: } \\
\quad 11.0(10.5 \text { to } 11.5)]\end{array}$} \\
\hline$\leq 18$ & 1 & - \\
\hline$>18$ to $\leq 25$ & $0.74(0.64$ to 0.86$)$ & 0.0001 \\
\hline$>25$ to $\leq 35$ & $0.87(0.75$ to 1.00$)$ & 0.05 \\
\hline$>35$ to $\leq 60$ & $0.99(0.87$ to 1.14$)$ & 0.91 \\
\hline$>60$ & $1.38(1.21$ to 1.57$)$ & 0.0001 \\
\hline Not known & $0.18(0.13$ to 0.24$)$ & 0.0001 \\
\hline$/ \log _{2}$ increment & $1.14(1.10$ to 1.18$)$ & 0.0001 \\
\hline \multicolumn{3}{|c|}{$\begin{array}{l}\text { Liver-related mortality [329 events, } 202,727 \text { PYFU, rate }(95 \% \text { CI }) / 1000 \\
\text { PYFU: } 1.62(1.45 \text { to } 1.80)]\end{array}$} \\
\hline$\leq 18$ & 1 & - \\
\hline$>18$ to $\leq 25$ & $0.96(0.49$ to 1.89$)$ & 0.91 \\
\hline$>25$ to $\leq 35$ & 2.01 (1.13 to 3.56$)$ & 0.02 \\
\hline$>35$ to $\leq 60$ & $4.08(2.44$ to 6.85$)$ & 0.0001 \\
\hline$>60$ & $6.88(4.15$ to 11.40$)$ & 0.0001 \\
\hline Not known & $0.59(0.24$ to 1.48$)$ & 0.26 \\
\hline$/ \log _{2}$ increment & $1.58(1.45$ to 1.72$)$ & 0.0001 \\
\hline \multicolumn{3}{|c|}{$\begin{array}{l}\text { Diabetes [ } 922 \text { events, } 198,079 \text { PYFU, rate }(95 \% \text { CI }) / 1000 \text { PYFU: } 4.78 \text { (4.47 } \\
\text { to 5.08)] }\end{array}$} \\
\hline$\leq 18$ & 1 & - \\
\hline$>18$ to $\leq 25$ & $1.05(0.80$ to 1.39$)$ & 0.72 \\
\hline$>25$ to $\leq 35$ & $1.50(1.16$ to 1.94$)$ & 0.002 \\
\hline$>35$ to $\leq 60$ & $2.15(1.68$ to 2.73$)$ & 0.0001 \\
\hline$>60$ & $2.86(2.24$ to 3.65$)$ & 0.0001 \\
\hline Not known & 2.08 (1.51 to 2.87$)$ & 0.0001 \\
\hline$/ \log _{2}$ increment & $1.33(1.26$ to 1.41$)$ & 0.0001 \\
\hline
\end{tabular}

*Adjusted for demographic and CVD risk factors and cumulative exposure to specific antiretroviral drugs, and recent exposure to drugs from the nucleoside reverse transcriptase inhibitor class.

the cohort. The strong association between a higher ALT level and an increased risk of liver-related mortality has been reported by others. ${ }^{3}$ Interestingly, we found a U-shaped association between ALT levels and all-cause mortality, with a higher mortality risk in those with very low and those with very high ALT levels. It is likely that the shape of any association with all-cause mortality will depend on the underlying causes of mortality in the cohort. Trends in causes of death in the D:A:D Study have recently been presented ${ }^{16}$; liver-related mortality currently accounts for $13 \%$ of deaths that have occurred, with deaths from MI accounting for $6 \%$.

We investigated whether the association between low ALT and a higher MI rate was driven by a higher rate of viral hepatitis (or injection drug use) in those with high ALT levels. Around $20 \%$ of follow-up time in the D:A:D Study is contributed by patients who are coinfected with $\mathrm{HCV}$ and $6 \%$ by those coinfected with hepatitis B virus ${ }^{19} ; 17.0 \%$ of patients in the present dataset were infected with HIV via injection drug use. Although we found a significant inverse association between MI risk and ALT levels regardless of HCV status or injection drug use, the associations did appear to be numerically greater in those who were HCV positive and in those who were infected with HIV through injection drug use (note that these groups largely overlap). The differences between these subgroups were not significant, however, suggesting that any differences may simply reflect chance variation. Furthermore, the fact that Ford's study was conducted within the general population, where only a small proportion of individuals would be expected to have viral infections or to be injection drug users, suggests that the association is unlikely to be driven by these factors.

Exposure to some antiretroviral drugs, particularly nevirapine and ritonavir, is associated with hepatotoxicities and raised ALT levels; the nucleoside reverse transcriptase inhibitors, stavudine and didanosine (and possibly zidovudine), may also cause hepatic steatosis that would tend to lead to elevated ALT levels. ${ }^{7-10,20}$ It is unlikely that a greater exposure to these drugs could explain the lower risk of MI in those with high ALT levels for 2 reasons. First, if this were to explain our findings, the drugs that are most likely to cause ALT elevations would also have to be associated with a reduced MI risk; the only antiretroviral drug where this might plausibly be the case is nevirapine, which is associated with a more favorable lipid profile. ${ }^{21}$ Secondly, our associations were similar both before and after adjustment for cumulative exposure to specific antiretroviral drugs and to current exposure to drugs from the nucleoside reverse transcriptase inhibitor class. Thus, we do not believe that this is an explanation for our findings.

Results from a recent meta-analysis of 72 randomized trials of statins found that statin treatments significantly increased the rate of elevated ALT levels. ${ }^{17}$ As statin treatment would reduce the risk of MI in those receiving them, this might induce an inverse relationship between ALT levels and MI risk. However, the inverse association was not removed after adjustment for either the lipid levels themselves or for the use of lipid-lowering drugs as a class (note that the data collection for the D:A:D Study does not allow us to differentiate between statins and other lipid-lowering drugs). Thus, we do not believe that this is a likely explanation for our findings.

Finally, it should be noted that our multivariable regression model included adjustment for current smoking status. Hence, although cigarette smoking is a known risk factor for MI and may also lead to a reduction in ALT levels, it cannot explain the associations seen. Although we do not capture more detailed information on pack-years or number of cigarettes smoked, we would not expect this to confound any associations with ALT and so do not believe that this additional information would change our conclusions.

Several limitations of our study must be noted. Firstly, we do not collect information on alcohol use among participants. It has been suggested that a moderate intake of alcohol may be beneficial to the coronary arteries ${ }^{22}$ and alcohol is known to increase ALT levels, ${ }^{23}$ thus possibly explaining the observed inverse association between increasing ALT levels and MI risk. However, it should be noted that the findings by Ford et $\mathrm{al}^{6}$ were adjusted for alcohol consumption, and so this did not appear to explain the inverse association in their study. Furthermore, we did not find a similarly strong inverse association with the CHD end point, although alcohol may also be expected to lead to a reduced risk of this broader end point. As ALT levels were not routinely 
measured systematically in individuals with HIV until relatively recently and not all cohorts routinely captured these measurements, our analyses could only include patients from 8 of the 11 participating cohorts. However, although this reduces the amount of follow-up that can be used in analysis, it does result in a more contemporaneous population increasing the clinical relevance of the findings to current treatment protocols. Given the characteristics of the patients in the D:A:D Study, our results are generalizable to a largely male population. As an observational study, our analyses are always subject to the possibility of unmeasured confounding and other potential sources of bias, limiting any statements regarding a causal association between lower ALT levels and MI risk. Finally, although the normal ALT range differs between men and women, the small number of women in the study and their lower MI risk limits our ability to perform stratified analyses by gender.

In summary, we confirm that higher ALT levels are associated with a lower MI risk in the D:A:D Study, but with higher risks of liver-related mortality and diabetes mellitus. As yet, there is no identified biological mechanism to explain the association between a low ALT level and a higher MI risk; although it is interesting to speculate that such individuals might be younger or healthier, we see no reason why this group should have an increased risk of MI. Furthermore, we are unaware of any clinical conditions or factors that would lead to lower than normal ALT levels that might lead to the higher MI risk. Thus, it is hard to comment on the clinical implications of these findings at this stage. Rather, in replicating the findings of Ford et $\mathrm{al}^{6}$ in a different setting, we hope to encourage other research groups to investigate possible biological mechanisms.

\section{ACKNOWLEDGMENT}

The authors thank $F$. Gustafsson for providing valuable input to the current project.

\section{REFERENCES}

1. Miyake T, Kumagi T, Hirooka M, et al. Metabolic markers and ALT cutoff level for diagnosing non-alcoholic fatty liver disease: a community-based cross-sectional study. J Gastroenterol. 2012;47:696-703.

2. Bansi L, Gazzard B, Post F, et al. Biomarkers measured to monitor safety in people on ART and risk of mortality. J Acquir Immune Defic Syndr. 2012;60:51-58.

3. Ruhl CE, Everhart JE. Elevated serum alanine aminotransferase and gamma-glutamyltransferase and mortality in the United States population. Gastroenterology. 2009;136:477-485.

4. Goessling W, Massaro JM, Vasan RS, et al. Aminotransferase levels and 20-year risk of metabolic syndrome, diabetes, and cardiovascular disease. Gastroenterology. 2008;135:1935-1944.

5. Price JC, Seaberg EC, Badri S, et al. HIV monoinfection is associated with increased aspartate aminotransferase-to-platelet ratio index, a surrogate marker for hepatic fibrosis. J Infect Dis. 2012;205:1005-1013.

6. Ford I, Mooijaart SP, Lloyd S, et al. The inverse relationship between alanine aminotransferase in the normal range and adverse cardiovascular and non-cardiovascular outcomes. Int J Epidemiol. 2011;40:1530-1538.

7. Bansi L, Turner J, Gilson R, et al. Is 1 alanine transaminase $>200$ IU enough to define an alanine transaminase flare in HIV-infected populations? A new definition derived from a large cohort study. J Acquir Immune Defic Syndr. 2009;52:391-396.

8. Vogel M, Rockstroh JK. Hepatotoxicity and liver disease in the context of HIV therapy. Curr Opin HIV AIDS. 2007;2:306-313.
9. Wit F, Weverling G, Weel J, et al. Incidence of and risk factors for severe hepatotoxicity associated with antiretroviral combination therapy. $J$ Infect Dis. 2002;186:23-31.

10. Kovari H, Ledergerber B, Battegay $M$, et al. Incidence and risk factors for chronic elevation of alanine aminotransferase levels in HIV-infected persons without hepatitis B or C virus co-infection. Clin Infect Dis. 2010; 50:502-511.

11. Triant VA. HIV infection and coronary heart disease: an intersection of epidemics. J Infect Dis. 2012;205(suppl 3):S355-S361.

12. Baker JV, Lundgren JD. Cardiovascular implications from untreated human immunodeficiency virus infection. Eur Heart J. 2011;32: 945-951.

13. Worm SW, Sabin C, Weber R, et al. Risk of myocardial infarction in patients with HIV infection exposed to specific individual antiretroviral drugs from the 3 major drug classes: the data collection on adverse events of anti-HIV drugs (D:A:D) study. J Infect Dis. 2010:201:318-330.

14. Friis-Moller N, Weber R, Reiss P, et al. Cardiovascular disease risk factors in HIV patients: association with antiretroviral therapy. Results from the DAD study. AIDS. 2003;17:1179-1193.

15. Kowalska JD, Friis-Moller N, Kirk O, et al. The Coding Causes of Death in HIV (CoDe) Project: initial results and evaluation of methodology. Epidemiology. 2011;22:516-523.

16. Weber R, Smith C, D:A:D Study Group. Trends over time in underlying causes of death in the D:A:D Study from 1999-2011. Abstract THAB0304. XIX International AIDS Conference. Washington, DC; 2012.

17. Alberton M, Wu P, Druyts E, et al. Adverse events associated with individual statin treatments for cardiovascular disease: an indirect comparison meta-analysis. QJM. 2012;105:145-157.

18. Schindhelm RK, Dekker JM, Nijpels G, et al. Alanine aminotransferase predicts coronary heart disease events: a 10-year follow-up of the Hoorn Study. Atherosclerosis. 2007;191:391-396.

19. The Data Collection on Adverse Events of Anti-HIV Drugs (D:A:D) Study Group. HBV or HCV coinfections and risk of myocardial infarction in HIV-infected individuals: the D:A:D Cohort Study. Antivir Ther. 2010;15:1077-1086.

20. Kovari H, Weber R. Influence of ART on liver disease. Curr Opin HIV AIDS. 2011;6:272-277.

21. Podzamcszer D, Andrade-Villanueva J, Clotet B, et al. Lipid profiles for nevirapine vs. atazanavir/ritonavir, both combined with tenofovir disoproxil fumarate and emtricitabine over 48 weeks, in treatment-naïve HIV-1infected patients (the ARTEN study). HIV Med. 2011;12:374-382.

22. Zyriax BC, Lau K, Klahn T, et al. Association between alcohol consumption and carotid intima-media thickness in a healthy population: data of the STRATEGY study (Stress, Atherosclerosis and ECG Study). Eur J Clin Nutr. 2010;64:1199-1206.

23. Tsai J, Ford ES, Li C, et al. Past and current alcohol consumption patterns and elevations in serum hepatic enzymes among US adults. Addict Behav. 2012;37:78-84.

\section{APPENDIX 1} with *)

D:A:D participating cohorts and Steering Committee (names marked

Members of the D:A:D SC from the Oversight Committee: N. Shortman*, D. Butcher*, R. Rode*, X. Franquet*, W. Powderly*.

D:A:D Central Coordination: L. Ryom, C. A. Sabin*, D. Kamara, C. Smith, A. Phillips*, A. Mocroft, J. Tverland, J. Nielsen, J. D. Lundgren (chair).

D:A:D Data Managers: R. Salbøl Brandt (coordinator), M. Rickenbach, I. Fanti, E. Krum, M. Hillebregt, S. Geffard, A. Sundström, M. Delforge, E. Fontas, F. Torres, H. McManus, S. Wright, J. Kjær.

Endpoint Verification Group: A. Sjøl (CVD primary endpoint), P. Meidahl (oncology), J. Helweg-Larsen (hematology), J. Schmidt Iversen (nephrology).

The members of the 11 Cohorts are as follows:

ATHENA (AIDS Therapy Evaluation Project Netherlands):

Central coordination: F. de Wolf, S. Zaheri, M Hillebregt L. Gras.

Participating physicians ( $\propto$ indicates Site coordinating physicians): Academisch Medisch Centrum bij de Universiteit van Amsterdam, Amsterdam: J. M. Prinsa, T. W. Kuijpers, H. J. Scherpbier, K. Boer, J. T. M. van der Meer, F. W. M. N. Wit, M. H. Godfried, P. Reiss*, T. van der Poll, F. J. B. Nellen, 
J. M. A. Lange, S. E. Geerlings, M. van Vugt, S. M. E. Vrouenraets, D. Pajkrt, M. van der Valk. Academisch Ziekenhuis Maastricht, Maastricht: G. Schreija, S. Lowe, A. Oude Lashof. Catharina-ziekenhuis, Eindhoven: M. J. H. Pronko, B. Bravenboer. Erasmus Medisch Centrum, Rotterdam: M. E. van der Ended, T. E. M. S. de Vries-Sluijs, C. A. M. Schurink, M. van der Feltz, J. L. Nouwen, L. B. S. Gelinck, A. Verbon, B. J. A. Rijnders, L. Slobbe. Erasmus Medisch Centrum-Sophia, Rotterdam: N. G. Hartwig, G. J. A. Driessen. Flevoziekenhuis, Almere: J. Brangera. HagaZiekenhuis, Den Haag: R. H. Kauffmanna, E. F. Schippers. Isala Klinieken, Zwolle: P. H. P. Groenevelda, M. A. Alleman, J. W. Bouwhuis. Kennemer Gasthuis: R. W. ten Kated, R. Soetekouw. Leids Universitair Medisch Centrum, Leiden: F. P. Kroong, P. J. van den Broek, J. T. van Dissel, S. M. Arend, C. van Nieuwkoop, M. G. J. de Boer, H. Jolink. Maasstadziekenhuis, Rotterdam: J. G. den Hollandera, K. Pogany. Medisch Centrum Alkmaar, Alkmaar: G. van Twillerto, W. Kortmann. Medisch Centrum Haaglanden, Den Haag: R. Vriesendorpa, E. M. S. Leyten. Medisch Spectrum Twente, Enschede: C. H. H. ten Napela, G. J. Kootstra. Onze Lieve Vrouwe Gasthuis, Amsterdam: K. Brinkmana, W. L. Blok, P. H. J. Frissen, W. E. M. Schouten, G. E. L. van den Berk. Sint Elisabeth Ziekenhuis, Tilburg: J. R. Juttmanna, M. E. E. van Kasteren, A. E. Brouwer. Sint Lucas Andreas Ziekenhuis, Amsterdam: J. Veenstrad, K. D. Lettinga. Slotervaartziekenhuis, Amsterdam: J. W. Muldera, E. C. M. van Gorp, P. M. Smit, S. Weijer. Stichting Medisch Centrum Jan van Goyen, Amsterdam: A. van Eeden, D. W. M. Verhagena. Universitair Medisch Centrum Groningen, Groningen: H. G. Sprenger a, R. Doedens, E. H. Scholvinck, S. van Assen, C. J. Stek. Universitair Medisch Centrum Sint Radboud, Nijmegen: P. P. Koopmansa, R. de Groot, M. Keuter, A. J. A. M. van der Ven, H. J. M. ter Hofstede, M. van der Flier, A. M. Brouwer, A. S. M. Dofferhoff. Universitair Medisch Centrum Utrecht, Utrecht: A. I. M. Hoepelmanø, T. Mudrikova, M. M. E. Schneider, C. A. J. J. Jaspers, P. M. Ellerbroek, E. J. G. Peters, L. J. Maarschalk-Ellerbroek, J. J. Oosterheert, J. E. Arends, M. W. M. Wassenberg, J. C. H. van der Hilst. Vrije Universiteit Amsterdam, Amsterdam: S. A. Dannera, M. A. van Agtmael, J. de Vocht, R. M. Perenboom, F. A. P. Claessen, W. F. W. Bierman, E. V. de Jong, E. A. bij de Vaate. Wilhelmina Kinderziekenhuis, Utrecht: S. P. M. Geelen, T. F. W. Wolfs. Ziekenhuis Rijnstate, Arnhem: C. Richtero, J. P. van der Berg, E. H. Gisolf. Ziekenhuis Walcheren, Vlissingen: M. van den Bergeo, A. Stegeman. Medisch Centrum Leeuwarden, Leeuwarden: D. P. F. van Houted, M. B. Polée, M. G. A. van Vonderen. Sint Elisabeth Hospitaal, Willemstad - Curaçao: C. Winkel, A. J. Duits.

ANRS CO3 Aquitaine Cohort (France)

Composition of the Groupe d'Epidémiologie Clinique du Sida en Aquitaine (GECSA):

Coordination: F. Dabis*. Scientific committee: F. Bonnet, F. Dabis, M. Dupon, G. Chêne, H. Fleury, D. Lacoste, D. Malvy, P. Mercié, I. Pellegrin, P. Morlat, D. Neau, JL. Pellegrin, R. Thiébaut, K. Titier. Epidemiology and Methodology: M. Bruyand, G. Chêne, F. Dabis, S. Lawson-Ayayi, R. Thiébaut, L. Wittkop. Infectious Diseases and Internal Medicine: F. Bonnal, F. Bonnet, N. Bernard, L. Caunègre, C. Cazanave, J. Ceccaldi, D. Chambon, I. Chossat, K. Courtaud, FA. Dauchy, S. De Witte, M. Dupon, A. Dupont, P. Duffau, H. Dutronc, S. Farbos, V. Gaboriau, MC. Gemain, Y. Gerard, C. Greib, M. Hessamfar, D. Lacoste, P. Lataste, S. Lafarie-Castet, E. Lazaro, M. Longy-Boursier, D. Malvy, JP. Meraud, P. Mercié, E. Monlun, P. Morlat, D. Neau, A. Ochoa, JL. Pellegrin, T. Pistone, JM. Ragnaud, MC. Receveur, J. Roger-Schmeltz, S. Tchamgoué, P. Thibaut, MA. Vandenhende, JF. Viallard. Immunology: JF. Moreau, I. Pellegrin. Virology: H. Fleury, ME. Lafon, B. Masquelier, P. Trimoulet. Pharmacology: D. Breilh, K. Titier. Drug monitoring: F. Haramburu, G. Miremont-Salamé. Data collection and processing: MJ. Blaizeau, M. Decoin, J. Delaune, S. Delveaux, C. D'Ivernois, C. Hanappier, O. Leleux, B. Uwamaliya-Nziyumvira, X. Sicard. Computing and Statistical analysis: S. Geffard, J. Leray, G. Palmer, D. Touchard.

AHOD (Australian HIV Observational Database, Australia):

Central coordination: M. Law *, K. Petoumenos, H. McManus, S. Wright, C. Bendall (Sydney, New South Wales).

Participating physicians (city, state): R. Moore, S. Edwards, J. Hoy, K. Watson, N. Roth, J. Nicholson (Melbourne, Victoria); M Bloch, T. Franic,
D. Baker, R. Vale, A. Carr, D. Cooper (Sydney, New South Wales); J. Chuah, M. Ngieng (Gold Coast, Queensland), D. Nolan, J. Skett (Perth, Western Australia).

\section{BASS (Spain):}

Central coordination: G. Calvo, F. Torres, S. Mateu (Barcelona).

Participating physicians (city): P. Domingo, M. A. Sambeat, J. Gatell, E. Del Cacho, J. Cadafalch, M. Fuster (Barcelona); C. Codina, G. Sirera, A. Vaqué (Badalona).

The Brussels St Pierre Cohort (Belgium): Coordination: S. De Wit*, N. Clumeck, M. Delforge, C. Necsoi. Participating physicians: N. Clumeck, S. De Wit, AF Gennotte, M. Gerard, K. Kabeya, D. Konopnicki, A. Libois, C. Martin, M. C. Payen, P. Semaille, Y. Van Laethem.

CPCRA (USA):

Central coordination: J. Neaton, G. Bartsch, W. M. El-Sadr*, E. Krum, G. Thompson, D. Wentworth

Participating physicians (city, state): R. Luskin-Hawk (Chicago, IL); E. Telzak (Bronx, NY); W. M. El-Sadr (Harlem, NY); D. I. Abrams (San Francisco, CA); D. Cohn (Denver, CO); N. Markowitz (Detroit, MI); R. Arduino (Houston, TX); D. Mushatt (New Orleans, LA); G. Friedland (New Haven, CT); G. Perez (Newark, NJ); E. Tedaldi (Philadelphia, PA); E. Fisher (Richmond, VA); F. Gordin (Washington, DC); L. R. Crane (Detroit, MI); J. Sampson (Portland, OR); J. Baxter (Camden, NJ).

EuroSIDA (multinational)

Coordinating Centre: J. Lundgren*, O. Kirk*, A. Mocroft, A. CozziLepri, D. Grint, D. Podlekareva, J. Kjær, L. Peters, J. Reekie, J. Kowalska, J. Tverland, A. H. Fischer, J. Nielsen.

Participating countries and physicians Argentina: (M. Losso), C. Elias, Hospital JM Ramos Mejia, Buenos Aires.

Austria: (N. Vetter), Pulmologisches Zentrum der Stadt Wien, Vienna; R. Zangerle, Medical University Innsbruck, Innsbruck.

Belarus: (I. Karpov), A. Vassilenko, Belarus State Medical University, Minsk; V. M. Mitsura, Gomel State Medical University, Gomel; O. Suetnov, Regional AIDS Centre, Svetlogorsk.

Belgium: (N. Clumeck), S. De Wit, M Delforge, Saint-Pierre Hospital, Brussels; R. Colebunders, Institute of Tropical Medicine, Antwerp; L. Vandekerckhove, University Ziekenhuis Gent, Gent.

Bosnia-Herzegovina: (V. Hadziosmanovic), Klinicki Centar Univerziteta Sarajevo, Sarajevo.

Bulgaria: (K. Kostov), Infectious Diseases Hospital, Sofia.

Croatia: (J. Begovac), University Hospital of Infectious Diseases, Zagreb.

Czech Republic: (L. Machala), D. Jilich, Faculty Hospital Bulovka, Prague; D. Sedlacek, Charles University Hospital, Plzen.

Denmark: (J. Nielsen), G. Kronborg, T. Benfield, M. Larsen, Hvidovre Hospital, Copenhagen; J. Gerstoft, T. Katzenstein, A-B. E. Hansen, P. Skinhøj, Rigshospitalet, Copenhagen; C. Pedersen, Odense University Hospital, Odense; L. Ostergaard, Skejby Hospital, Aarhus.

Estonia: (K. Zilmer), West-Tallinn Central Hospital, Tallinn; J. Smidt, Nakkusosakond Siseklinik, Kohtla-Järve.

Finland: (M. Ristola), Helsinki University Central Hospital, Helsinki.

France: (C. Katlama), Hôpital de la Pitié-Salpétière, Paris; J-P. Viard, Hôpital Necker-Enfants Malades, Paris; P-M. Girard, Hospital Saint-Antoine, Paris; J. M. Livrozet, Hôpital Edouard Herriot, Lyon; P. Vanhems, University Claude Bernard, Lyon; C. Pradier, Hôpital de l'Archet, Nice; F. Dabis, D. Neau, Unité INSERM, Bordeaux.

Germany: (J. Rockstroh), Universitäts Klinik Bonn; R. Schmidt, Medizinische Hochschule Hannover; J. van Lunzen, O. Degen, University Medical Center Hamburg-Eppendorf, Infectious Diseases Unit, Hamburg; H. J. Stellbrink, IPM Study Center, Hamburg; S. Staszewski, JW Goethe University Hospital, Frankfurt; J. Bogner, Medizinische Poliklinik, Munich; G. Fätkenheuer, Universität Köln, Cologne.

Greece: (J. Kosmidis), P. Gargalianos, G. Xylomenos, J. Perdios, Athens General Hospital; G. Panos, A. Filandras, E. Karabatsaki, first IKA Hospital; H. Sambatakou, Ippokration Genereal Hospital, Athens. 
Hungary: (D. Banhegyi), Szent Lásló Hospital, Budapest.

Ireland: (F. Mulcahy), St. James's Hospital, Dublin.

Israel: (I. Yust), D. Turner, M. Burke, Ichilov Hospital, Tel Aviv; S. Pollack, G. Hassoun, Rambam Medical Center, Haifa; S. Maayan, Hadassah University Hospital, Jerusalem.

Italy: (S. Vella), Istituto Superiore di Sanità, Rome; R. Esposito, I. Mazeu, C. Mussini, Università Modena, Modena; C. Arici, Ospedale Riuniti, Bergamo; R. Pristera, Ospedale Generale Regionale, Bolzano; F. Mazzotta, A. Gabbuti, Ospedale S Maria Annunziata, Firenze; V. Vullo, M. Lichtner, University di Roma la Sapienza, Rome; A. Chirianni, E. Montesarchio, M. Gargiulo, Presidio Ospedaliero AD Cotugno, Monaldi Hospital, Napoli; G. Antonucci, A. Testa, P. Narciso, C. Vlassi, M. Zaccarelli, Istituto Nazionale Malattie Infettive Lazzaro Spallanzani, Rome; A. Lazzarin, A. Castagna, N. Gianotti, Ospedale San Raffaele, Milan; M. Galli, A. Ridolfo, Osp. L. Sacco, Milan; A. d'Arminio Monforte, Istituto Di Clinica Malattie Infettive e Tropicale, Milan.

Latvia: (B. Rozentale), I. Zeltina, Infectology Centre of Latvia, Riga. Lithuania: (S. Chaplinskas), Lithuanian AIDS Centre, Vilnius.

Luxembourg: (R. Hemmer), T. Staub, Centre Hospitalier, Luxembourg.

Netherlands: (P. Reiss*), Academisch Medisch Centrum bij de Universiteit van Amsterdam, Amsterdam.

Norway: (V. Ormaasen), A. Maeland, J. Bruun, Ullevål Hospital, Oslo. Poland: (B. Knysz), J. Gasiorowski, Medical University, Wroclaw; A. Horban, E. Bakowska, Centrum Diagnostyki i Terapii AIDS, Warsaw; A. Grzeszczuk, R. Flisiak, Medical University, Bialystok; A. BoronKaczmarska, M. Pynka, M. Parczewski, Medical Univesity, Szczecin; M. Beniowski, E. Mularska, Osrodek Diagnostyki i Terapii AIDS, Chorzow; H. Trocha, Medical University, Gdansk; E. Jablonowska, E. Malolepsza, K. Wojcik, Wojewodzki Szpital Specjalistyczny, Lodz.

Portugal: (F. Antunes), M. Doroana, L. Caldeira, Hospital Santa Maria, Lisbon; K. Mansinho, Hospital de Egas Moniz, Lisbon; F. Maltez, Hospital Curry Cabral, Lisbon.

Romania: (D. Duiculescu), Spitalul de Boli Infectioase si Tropicale: Dr. Victor Babes, Bucarest.

Russia: (A. Rakhmanova), Medical Academy Botkin Hospital, St Petersburg; N. Zakharova, St Petersburg AIDS Centre, St Peterburg; S. Buzunova, Novgorod Centre for AIDS, Novgorod.

Serbia: (D. Jevtovic), The Institute for Infectious and Tropical Diseases, Belgrade.

Slovakia: (M. Mokráš), D. Staneková, Dérer Hospital, Bratislava.

Slovenia: (J. Tomazic), University Clinical Centre Ljubljana, Ljubljana.

Spain: (J. González-Lahoz), V. Soriano, P. Labarga, J. Medrano, Hospital Carlos III, Madrid; S. Moreno, J. M. Rodriguez, Hospital Ramon y Cajal, Madrid; B. Clotet, A. Jou, R. Paredes, C. Tural, J. Puig, I. Bravo, Hospital Germans Trias i Pujol, Badalona; J. M. Gatell, J. M. Miró, Hospital Clinic i Provincial, Barcelona; P. Domingo, M. Gutierrez, G. Mateo, M. A. Sambeat, Hospital Sant Pau, Barcelona.

Sweden: (A. Karlsson), Venhaelsan-Sodersjukhuset, Stockholm; L. Flamholc, Malmö University Hospital, Malmö.

Switzerland: (B. Ledergerber), R. Weber, University Hospital, Zürich; P. Francioli, M. Cavassini, Centre Hospitalier Universitaire Vaudois, Lausanne; B. Hirschel, E. Boffi, Hospital Cantonal Universitaire de Geneve, Geneve; H. Furrer, Inselspital Bern, Bern; M. Battegay, L. Elzi, University Hospital Basel. Ukraine: (E. Kravchenko), N. Chentsova, Kiev Centre for AIDS, Kiev; V. Frolov, G. Kutsyna, Luhansk State Medical University; Luhansk; S. Servitskiy, Odessa Region AIDS Center, Odessa; M. Krasnov, Kharkov State Medical University, Kharkov.

United Kingdom: (S. Barton), St. Stephen's Clinic, Chelsea and Westminster Hospital, London; A. M. Johnson, D. Mercey, University College London, London (University College Campus); A. Phillips, M. A. Johnson,
A. Mocroft, Royal Free Hospital and University College London, London (Royal Free Campus); M. Murphy, Medical College of Saint Bartholomew's Hospital, London; J. Weber, G. Scullard, Imperial College School of Medicine at St. Mary's, London; M. Fisher, Royal Sussex County Hospital, Brighton; C. Leen, Western General Hospital, Edinburgh.

HivBivus (Sweden):

Central coordination: L. Morfeldt, G. Thulin, A. Sundström.

Participating physicians (city): B. Åkerlund (Huddinge); K. Koppel, A. Karlsson (Stockholm); L. Flamholc, C. Håkangård (Malmö)

The IcoNA Foundation Study (Italy):

Governing Body: M. Moroni (Chair), G. Angarano, A. Antinori, F. Castelli, R. Cauda, A. d'Arminio Monforte*, G. Di Perri, M. Galli, R. Iardino, G. Ippolito, A. Lazzarin, C. F. Perno, O. Armignacco, P. L. Viale, F. Von Schlosser.

Scientific Secretary: A d'Arminio Monforte.

Steering Committee: A. Ammassari, M. Andreoni, A. Antinori, C. Balotta, P. Bonfanti, S. Bonora, M. Borderi, M. R. Capobianchi, A Castagna, F. Ceccherini-Silberstein, P. Cinque, A. Cozzi-Lepri, A d'Arminio Monforte, A. De Luca, M. Gargiulo, C. Gervasoni, E. Girardi, A. Gori, G. Guaraldi, M. Lichtner, S. Lo Caputo, G. Madeddu, F. Maggiolo, G. Marchetti, S. Marcotullio, L. Monno, R. Murri, C. Mussini, M. Puoti, C. Torti. Statistical and Monitoring Team: A. Cozzi-Lepri, P. Cicconi, I. Fanti, T. Formenti, L. Galli, P. Lorenzini.

Participating Physicians and Centers: Italy A. Giacometti, A Costantini, A. Riva (Ancona); G. Angarano, L. Monno, C. Carrisa, (Bari); F. Maggiolo, G. Lazzari (Bergamo); P. L. Viale, M. Borderi, G. Verucchi (Bologna); F. Castelli, C. Torti, C. Minardi, (Brescia); T. Quirino, C. Abeli (Busto Arsizio); P. E. Manconi, P. Piano (Cagliari); J. Vecchiet, K. Falasca (Chieti); L. Sighinolfi, D. Segala (Ferrara); F. Mazzotta, S. Lo Caputo (Firenze); G. Cassola, G. Viscoli, A. Alessandrini, R. Piscopo, G. Mazzarello (Genova); C. Mastroianni, V. Belvisi (Latina); P. Bonfanti, I. Caramma (Lecco); A. Chiodera, P. Castelli (Macerata); M. Galli, A. Lazzarin, G. Rizzardini, M. Puoti, A. d'Arminio Monforte, A. L. Ridolfo, R. Piolini, A. Castagna, S. Salpietro, A. Galli, A. Bigoloni, V. Spagnuolo, L. Carenzi, P. Zucchi, M. C. Moioli, R. Rossotti, P. Cicconi, T. Formenti (Milano); C. Mussini, L. Bisio (Modena); A. Gori, G. Lapadula (Monza), N. Abrescia, A. Chirianni, M. G. Guida, M. Gargiulo (Napoli); F. Baldelli, B. Belfiori (Perugia); G. Parruti, T. Ursini (Pescara); G. Magnani, M. A. Ursitti (Reggio Emilia); R. Cauda, M. Andreoni, A. Antinori, V. Tozzi, V. Vullo, A. De Luca, A d'Avino, M. Zaccarelli, L. Gallo, E. Nicastro, R. Acinapura, M. Capozzi, R. Libertone, M. Lichtner, G. Tebano, (Roma); M. S. Mura, G. Madeddu (Sassari); P. Caramello, G. Di Perri, G. C. Orofino, M. Sciandra (Torino); G. Pellizzer, V. Manfrin (Vicenza).

Nice HIV Cohort (France):

Central coordination: C. Pradier*, E. Fontas, C. Caissotti.

Participating physicians: P. Dellamonica, E. Bernard, E. Cua, F. De Salvador-Guillouet, J. Durant, S. Ferrando, V. Mondain-Miton, A. Naqvi, I. Perbost, B. Prouvost-Keller, S. Pillet, P. Pugliese, V. Rahelinirina, P. M. Roger.

Clinical research assistant: K. Dollet.

SHCS (Swiss HIV Cohort Study, Switzerland)

J. Barth, M. Battegay, E. Bernasconi, J. Böni, H. C. Bucher, C. Burton-Jeangros, A. Calmy, M. Cavassini, C. Cellerai, R. Dubs, M. Egger, L. Elzi, J. Fehr, M. Flepp, P. Francioli (President of the SHCS), H. Furrer, C A. Fux, M. Gorgievski, H. Günthard, B. Hasse, H. H. Hirsch, B. Hirschel, I. Hösli, C. Kahlert, L. Kaiser, O. Keiser, C. Kind, T. Klimkait, H. Kovari, B Ledergerber, G. Martinetti, B. Martinez de Tejada, N. Müller, D. Nadal, G. Pantaleo, A. Rauch, S. Regenass, M. Rickenbach, C. Rudin, P. Schmid, D. Schultze, F. Schöni-Affolter, J. Schüpbach, R. Speck, P. Taffé, A. Telenti, A. Trkola, P. Vernazza, V. von Wyl, R. Weber*, S. Yerly. 